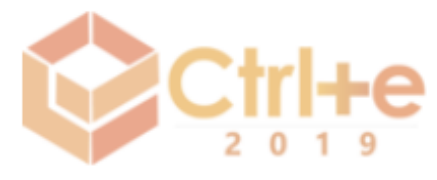

IV Congresso sobre Tecnologias na Educação (Ctrl+E 2019)

Recife, Pernambuco - Brasil

28 a 30 de agosto de 2019

\title{
O "Maker" na Escola: uma Reflexão sobre Tecnologia, Criatividade, e Responsabilidade Social
}

\author{
Lucas O. Lopes, Paula R. P. Oliveira, Karoline F. dos Santos, Elisa Pomari, Diego \\ Thuler
}

Desenvolvimento Pedagógico, Little Maker - Americana, SP - Brasil

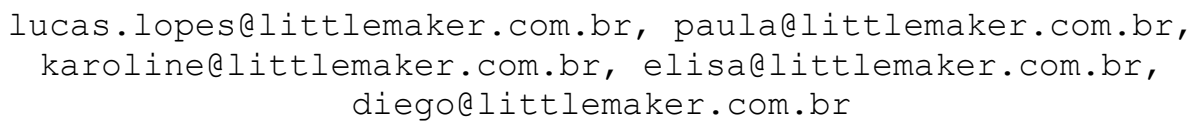

Resumo: $O$ artigo discute as possibilidades de desenvolvimento de consciência de responsabilidade social por meio de atividades maker exploradas em ambiente escolar, e suas consequências na formação do sujeito. A reflexão baseia-se num estudo de caso da metodologia da Little Maker aplicada a estudantes do Ensino Fundamental II.

\begin{abstract}
The article discusses the possibilities of developing social awareness and responsibility through the maker activities explored at school and its consequences in the students formation as individuals. The reflections are based on a study case of Little Maker's methodology applied to elementary school students.
\end{abstract}

\section{Introdução}

Muito se fala do valor pedagógico de metodologias ativas, tecnologias digitais aplicadas à sala de aula e dos múltiplos benefícios que tais atividades podem trazer para a formação do educando. Esse artigo não pretende negar tal aspecto, mas percorre um caminho diferente ao refletir sobre os possíveis impactos que tal formação pode trazer para a sociedade como um todo. Considerando que as pessoas formadas por essas metodologias podem desenvolver aguçada consciência e responsabilidade social e que isso pode ser incentivado de forma consciente por estratégias metodológicas e práticas pedagógicas.

Para tal, a reflexão parte da observação de uma atividade prática, a aplicação de um ciclo de aulas da metodologia Little Maker, realizada com estudantes do Ensino Fundamental II. Essa observação e a retomada de conceitos teóricos acerca de educação e tecnologias digitais guiam um estudo de caso que permitem considerações sobre o desenvolvimento de consciência e senso de responsabilidade social por meio de práticas como essa, assim como apontamentos sobre reverberações na sociedade a longo prazo.

Dessa forma, a seção 2 retoma o processo de surgimento do movimento maker e a sua entrada no ambiente escolar. Em seguida, são sublinhados alguns aspectos e possíveis impactos que a relação entre cultura maker e educação podem trazer para a sociedade. Essas observações sensibilizam o olhar para o estudo de caso descrito na seção 4. Por fim, são apresentados alguns apontamentos e reflexões acerca das possibilidades 
de desenvolvimento de consciência e senso de responsabilidade social abertas pela aplicação de metodologias ativas.

\section{O Movimento Maker: da garagem à escola}

Nascida da necessidade de formas mais econômicas de fazer reparos e manutenções residenciais e da customização de itens pessoais, a cultura do DIY - do-it-yourself, no inglês, ou faça você mesmo, em português - aliou-se ao conceito de open content conteúdo aberto - permitindo que as pessoas reproduzissem e modificassem projetos sem a necessidade de comprar ou pedir permissão ao autor. Essa é a origem do movimento de valorização da construção coletiva, o DIT - do-it-together ou faça junto, que, por sua vez, foi precursor do movimento maker. Tal movimento cresceu na medida em que reuniu pessoas que gostam essencialmente de criar e compartilhar seus projetos, nesse grupo encontram-se muitos hobistas e profissionais, principalmente da área de criação e tecnologia, dando origem a um manifesto que aponta seus alicerces por meio de palavras simples, mas que resumem bem a proposta: "participe, equipe-se, dedique-se, apoie, permita-se errar, aprenda, divirta-se, mude, faça e compartilhe" [Hatch, 2014]. A partir disso, tem início o que podemos chamar propriamente de Cultura Maker. Um conjunto de comportamentos, conhecimentos, valores, crenças e costumes que têm como base as ideias de que pessoas participativas podem se envolver em projetos que as façam se sentir capazes de construir coisas novas, ou seja, gerando seu empoderamento. Hoje a cultura maker se faz presente das garagens às universidades, passando por empresas, espaços colaborativos de criação, lugares de educação formal e informal. Como os maker spaces, onde os usuários valem-se de uma infraestrutura para criar e aprender a trabalhar com fabricação digital, programação, eletrônica, marcenaria e diversas outras habilidades técnicas; também é possível usar esses espaços para desenvolver projetos pessoais ou empresariais.

Por basear-se em saberes técnicos e sustentar-se pelos pilares de seu manifesto, a cultura maker estabeleceu profundo diálogo com campo educacional. Principalmente com concepções pedagógicas que perpassam as metodologias ativas, como é o caso da Aprendizagem Criativa, aqui entendida como aquela que coloca o aprendiz na posição de protagonista da construção do próprio saber; e da Aprendizagem Significativa, na qual as relações cognitiva, social e emocional do aprendiz com o objeto de conhecimento são valorizadas de forma integral, conectadas através do ambiente das tecnologias e técnicas, trazendo significado, compreensão, sentido, capacidade de transferência para o aprendiz [Santos e Galembeck, 2017].

Assim, em muitas escolas a aula de "maker" ou STEAM (Ciência, Arte, Tecnologia, engenharia, artes e matemática) divide espaço na grade com as disciplinas tradicionais, prometendo foco na interdisciplinaridade, no "mão-na-massa" e na

criatividade do aprendiz. A inserção de atividades maker no contexto escolar tem sido observada, discutida e estudada por diversos grupos de educadores e pesquisadores, dentre eles destacam-se o Project Zero da Graduate school of education de Harvard e o MediaLab do MIT [Clapp, E. P., Ross, J., Ryan, J. O. e Tishman, S. 2016].

\section{Cultura Maker: do sujeito para a sociedade}

A alfabetização na área de tecnologia é considerada por muitos como essencial no mundo contemporâneo [Santos e Schnetzler, 1997]. Essa ideia, aliada ao uso de ferramentas de uma oficina, do desenvolvimento de projetos que conectam ciência, arte, tecnologia, engenharia e matemática utilizando a liberdade da criatividade é instigante e soa como uma novidade empolgante para toda comunidade escolar. Porém, deve-se lembrar que criar ou construir algo no mundo é também intervir nesse mesmo mundo e, 
consequentemente, na vida dos outros. Em outras palavras, não se pode separar a construção e a criação individual ou de pequenos grupos de seu impacto coletivo e social. Assim, faz-se necessário levar o estudante a refletir sobre seu fazer, seu projeto ou sua criação, levando em consideração seu entorno e a sociedade para que, então, ele aja como cidadão.

Construir um projeto cuja finalidade encerra-se em si próprio pode parecer interessante num primeiro momento, como montar um robô por ser legal, apresentar uma oficina porque é diferente, inserir o STEAM pois são as habilidades do século XXI. Contudo, pode ser um caminho perigoso por levar o sujeito a entender que qualquer coisa por ele desenvolvida é boa pelo simples fato de ser um produto de sua criatividade. Acontecimentos dos dois últimos séculos nos lembram que ideias e adventos tecnológicos tanto podem melhorar a vida das pessoas como podem precariza-las. Tendo isso em vista, é indispensável que o ensino maker inclua reflexões sobre responsabilidade social no ambiente escolar. Para isso, é possível recorrer à abordagem CTS (Ciência, Tecnologia e Sociedade) empregada no ensino de ciências.

Desenvolvida e introduzida nos currículos desde a década de 1960, a abordagem CTS tem por objetivo trazer para o ensino de ciências, dentre outras coisas, o planejamento tecnológico e tomada de decisão para solução de problemas de importância social. Tais princípios foram incorporados nas discussões curriculares nacionais que, por este motivo, propõe: "identificar relações entre conhecimento científico, produção de tecnologia e condições de vida, no mundo de hoje e em sua evolução histórica, e compreender a tecnologia como meio para suprir necessidades humanas, sabendo elaborar juízo sobre riscos e benefícios das práticas científico-tecnológicas" [BRASIL, 1998]

Dessa forma, apesar do ensino maker não trabalhar exclusivamente com ciências e tecnologia, a abordagem CTS pode ser uma ferramenta pedagógica eficiente para introduzir no processo pedagógico, de maneira natural, as questões levantadas anteriormente.

\section{Little Maker: estudo de caso}

Este estudo de caso foi baseado nas aulas do curso Maker Inovador, um dos programas desenvolvidos pela Little Maker, cuja metodologia é organizada em quatro etapas principais - Ideação, Planejamento, Construção e Reflexão - subdivididas em alguns passos que estruturam a prática, conforme será visto a seguir. As aulas foram realizadas em um colégio da cidade de Campinas em dezembro de 2018. Nesse processo, foram envolvidos dez estudantes do Ensino Fundamental II com idades entre 11 e 14 anos, cujos nomes foram substituídos para garantir seu anonimato.

O curso Maker Inovador tem o intuito de ser aplicado de forma intracurricular, inserido na grade horária de todos os estudantes alunos com frequência semanal para o Ensino Fundamental II. Contudo, neste estudo de caso, o ciclo de aulas foi desenvolvido ao longo de quatro dias totalizando 16 horas.

\subsection{Ideação}

Imersão. O processo tem início a partir da apresentação de um micromundo que faz parte do programa em questão. Nesse caso, o micromundo explorado chama-se "Brasil Rural", nele algumas curiosidades a respeito do lugar são apresentadas aos estudantes para contribuir com a quebra de estereótipos ao mesmo passo em que desperta interesse sobre o assunto. Dessa forma, acredita-se que seja possível aproximar os Makers de realidades diferentes da sua de uma maneira mais aprofundada. A apresentação se dá por meio da 
figura de um amigo, um possível habitante que, de forma convidativa, inicia o processo de imersão.

Em seguida, foram apresentadas 4 estações de pesquisas organizadas por eixos de interesse onde os Makers poderiam agrupar-se livremente. A Maker Lara escolheu o "Eixo Animais e Vida". A partir de "perguntas provocação" - perguntas cuja função é iniciar um processo de pesquisa provocada por algumas curiosidades relacionadas ao micromundo - nele contidas, pesquisou sobre a pecuária intensiva e semi intensiva, muito sensibilizada pela questão de maus tratos aos animais na pecuária. Já o Maker Nico interessou-se pelo "Eixo Recursos Naturais", pois teve como ideia a criação de uma rede de compartilhamento de recursos entre áreas rurais, aproveitando o que cada lugar possuiria como potencial. Elementos como sustentabilidade, recursos hídricos e biológicos foram abordados. Dentro do "Eixo Trabalho, Produção e Infraestrutura", tivemos os Makers Edson, Carlos e Jorel. Partindo das possibilidades de transporte para deslocamento da produção da zona rural, os Makers aprofundaram-se na pesquisa de elementos como rodovias, linhas ferroviárias, hidrovias, entre outros, para compararem os custos e pensarem o que seria mais viável financeiramente. $\mathrm{O}$ grupo ficou tão envolvido que realizaram orçamentos reais. Além disso, discutiram quais produtos poderiam ser transportados para venda do campo para as áreas urbanas, levando em consideração o tempo de cultivo. Decidiram, então, pela produção e transporte de pimentas, por levarem de 20 a 60 dias entre plantio e colheita. Deste modo, eles tiveram como ideia um grande sistema de produção, transporte e venda de pimentas, que posteriormente foi batizado de Reinado das Pimentas. Os Makers Beto, Juju, Gigi, Jorge e William escolheram o "Eixo Cultura e Hábitos", problematizando o modo de vida das pessoas ali e pensando em como a tecnologia poderia contribuir para isso, quais recursos disponíveis poderiam ser aproveitado e como as pessoas poderiam se divertir neste lugar.

Compartilhamento Painéis. Após as pesquisas realizadas, os Makers de cada Eixo apresentaram um painel que construíram com as informações e pesquisas do lugar, compartilhando o conhecimento com os demais colegas, levando os Makers a escolherem em qual eixo gostariam de criar algo. Lara e Nico gostaram tanto da apresentação que os Makers fizeram do "Eixo de Trabalho, Produção e Infraestrutura" que decidiram se juntar ao Jorel, Edson e Carlos na ideia da produção de pimentas. Já Beto, Juju, Gigi, Jorge e William formaram um grupo para continuarem trabalhando questões do "Eixo Cultura e Hábitos", planejando construir um cinema ecologicamente sustentável para a população local.

Problematização. A partir do eixo escolhido, os grupos pensaram a problematização do lugar, entendendo as demandas através da criação das personas daquele ambiente. Após essas definições os grupos repensaram nas possíveis demandas e problemáticas do ambiente pesquisado pela perspectiva das personas construídas, a fim de identificar o que gostariam de abordar (ou validar, no caso do grupo do Reinado da Pimenta). O Grupo do "Eixo de Trabalho, Produção e Infraestrutura" mapeou como personas: um administrador para os negócios, uma coletora/colhedora de pimenta, um motorista de caminhão, um cozinheiro e um consumidor. Já o grupo do "Eixo Cultura e Hábitos" elaborou: responsável pela bilheteria, responsável pela manutenção técnica, administrador, responsável pela pipoqueira e uma persona representante do público.

\subsection{Planejamento}

Esboço de Projeto. Definidas as ideias, o grupo do Reinado da Pimenta dividiu-se em três subgrupos para construção de seu projeto: Jorel e Edson ficaram responsáveis pela parte estrutural do caminhão que faria o transporte dos produtos, enquanto Carlos e Nico 
ficaram responsáveis pelo funcionamento e movimento do caminhão, explorando com mais profundidade os elementos eletrônicos; já Lara ficou responsável pelo desenvolvimento do design das embalagens dos produtos, trabalhando, assim como Jorel e Edson, com técnicas manuais, combinando materiais e habilidades.

Enquanto isso, o outro grupo decidiu construir um cinema que aproveitasse de recursos naturais encontrados no ambiente para transformação em energia renovável, visando uma forma de diversão mais limpa sustentável para os moradores. A partir dessa premissa, dividiram-se em subgrupos também: Beto e Jorge ficaram responsáveis por explorar os eletrônicos a fim de construir o projetor do cinema; William ficou encarregado de estudar e explorar formas de converter a correnteza do rio em energia elétrica para a sala de cinema; Gigi ficou responsável pela construção da bilheteria do cinema, que incluía lanchonete; e Juju ficou encarregada pela construção da parte interna da sala de cinema, definindo texturas, materiais, as disposições das poltronas e do telão.
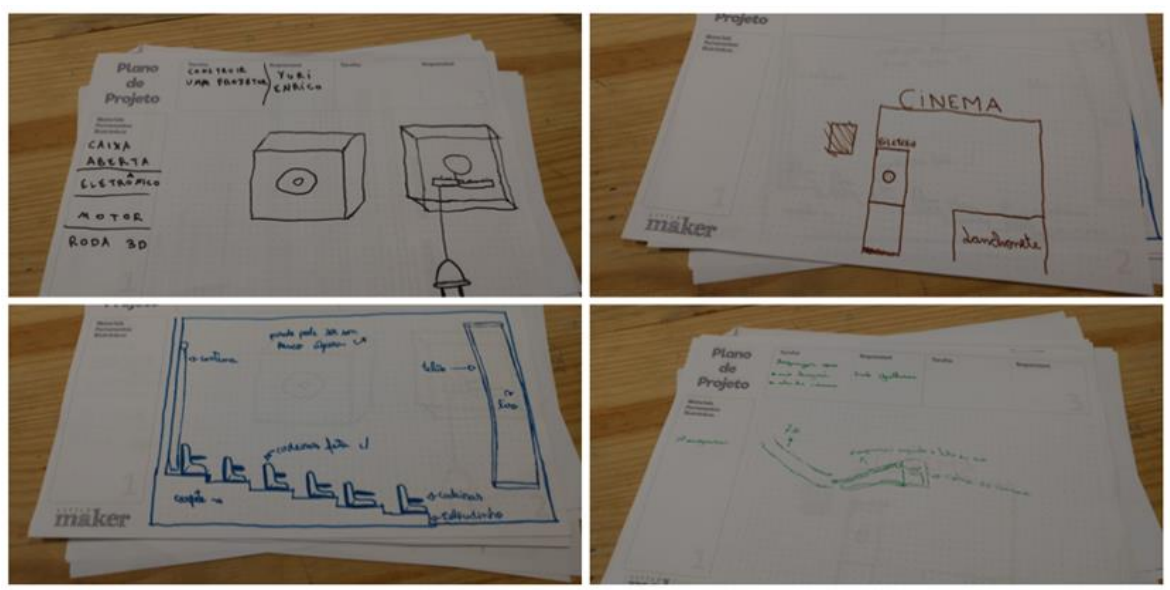

Figura 2 - Folhas de projetos com cada parte da construção do cinema

Mapa de Necessidades. Uma vez esboçadas as linhas gerais do projeto e levantadas as demandas do projeto, os Makers fizeram uma autoavaliação para entender os conhecimentos e habilidades necessários para construir o projeto e mapearam o que eles já sabem e o que precisavam aprender. Para isso usam como apoio os "Cards de Conhecimento e Habilidade" que ajuda a identificar as possibilidades e desdobramentos do projeto. Apesar dos grupos dividirem os projetos em subetapas que estavam intimamente ligadas, mantiveram uma comunicação estreita, a fim de que todas as partes fossem coerentes quando estivessem em conjunto, o que contribuiu para trocas de conhecimentos e exercícios de relações interpessoais importantes.
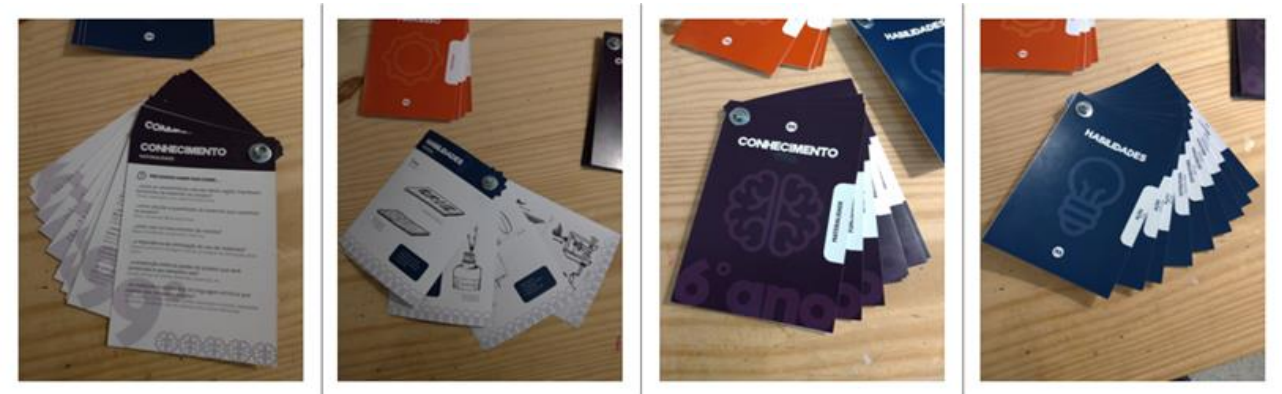

Figura 3 - Cards de Habilidades e Conhecimentos. Os cards dão suporte para
os alunos na elaboração dos mapas de necessidades.

Aquisição de Habilidades e Conhecimentos. Esse foi um importante momento de trocas, no qual os estudantes poderiam aprender conceitos e técnicas uns com os outros 
como tutores, visto que após aprenderem algo até então desconhecido, os Makers mostraram-se empolgados em dividir os conhecimentos ou habilidades. Como no caso da Caneta 3D, a qual Edson e Jorel exploraram a ferramenta e desenvolveram um método para que o manuseio fosse aprendido rapidamente: começar com formas básicas, como quadrados desenhados previamente em folha de sulfite e progressivamente avançar para construção de objetos tridimensionais a partir da junção de elementos bidimensionais. Esse método foi útil para a construção dos dois grupos.

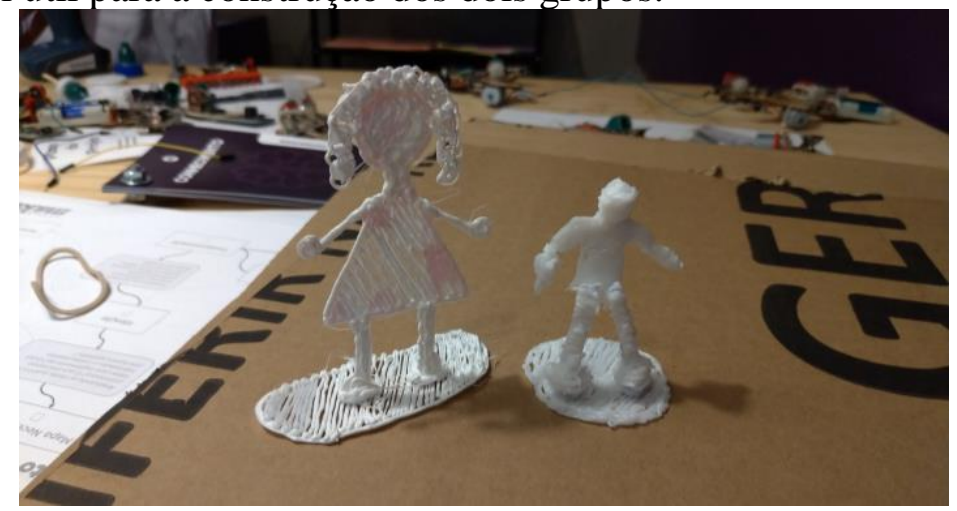

Figura 4 - Experimentações com a Caneta 3D. As duas figuras humanas foram criadas pelos alunos durante a etapa de aquisição de habilidades.

A Maker Juju realizou uma extensa pesquisa acerca de mecanismos que poderiam ajudar na construção do projetor do cinema, trazendo para a oficina conceitos e funcionamento de alavancas, polias, manivelas e diferentes tipos de engrenagens. Ainda no campo de pesquisas, o Maker Edson também trouxe um registro sobre como as descobertas científicas feitas na oficina poderiam ser úteis no projeto de seu grupo.

Em geral, a impressora 3D teve uma alta procura e, por isso, os estudantes puderam intercambiar experiências e informações a respeito das possibilidades da máquina; bem como os eletrônicos, que foram interessantes para ambos os projetos.

Adversidade. Após a aquisição dos conhecimentos e habilidades e antes de iniciar a construção do projeto de fato, foi apresentada uma adversidade. Essa etapa propõe uma retomada ao ambiente do micromundo, a elaboração de uma dificuldade que ali poderia ser encontrada e uma reavaliação do planejamento. Nesse caso, a adversidade proposta foi a ocorrência de um fenômeno natural e cada grupo teve que definir qual seria e como impactaria seu projeto.

O grupo do Reinado da Pimenta estabeleceu como adversidade, a partir da premissa de desastre natural, um incêndio que dificultaria a passagem do caminhão de transporte e, como solução, trabalharam em uma mudança na tração do caminhão, deixando-o mais forte e com mais rodas para passar por cima do entulho sem dificuldade. Já o grupo do Cinema, definiu que haveria uma seca no rio que serviria como provedor da água para energia. Optaram, então, por seguir com uma fonte de energia renovável, mas substituíram-na por energia solar, adaptando a recepção de energia para painéis solares.

Plano de Projeto. Após a adversidade os Makers fizeram as devidas adaptações aos planos de projeto esboçados inicialmente, considerando também os conhecimentos e habilidades adquiridas.

\subsection{Construção}

Prototipação. Ao longo do período de construção, algumas técnicas foram desenvolvidas e compartilhadas, como a descoberta de Juju quanto a pintar impressões 3D com giz de 
cera derretido através do contato com o bico da cola quente. Ela utilizou a técnica para colorir uma das poltronas do cinema e logo todos se interessaram e testaram. Apesar disso, julgou que o método não seria prático para aplicação em todas as poltronas e optou pela colagem de tecido como forma de revestimento das peças.

A Maker Gigi voltou a utilizar seus conhecimentos quanto ao manuseio da caneta 3D ao treinar letra cursiva para atender ao modelo de letreiro desejado para o cinema. Além disso, também utilizou a ferramenta para soldar o letreiro no papelão presente na estrutura da bilheteria. A caneta 3D também foi usada como instrumento para construção de uma coroa presente na embalagem de molho de pimenta, por Lara - que veio a utilizar a técnica de coloração por giz de cera também -, e para construir as laterais da cabine do caminhão do grupo Reinado da Pimenta: Edson e Jorel ficaram responsáveis cada um por uma lateral, eles puderam expressar estilos de preenchimento diferentes e refinar seu senso de tempo, ao perceberem quanto tempo levou para realizar essa tarefa em detrimento a outras que precisavam ser feitas; essa habilidade é vantajosa a longo prazo, por ser importante na hora de planejar o projeto e suas etapas.

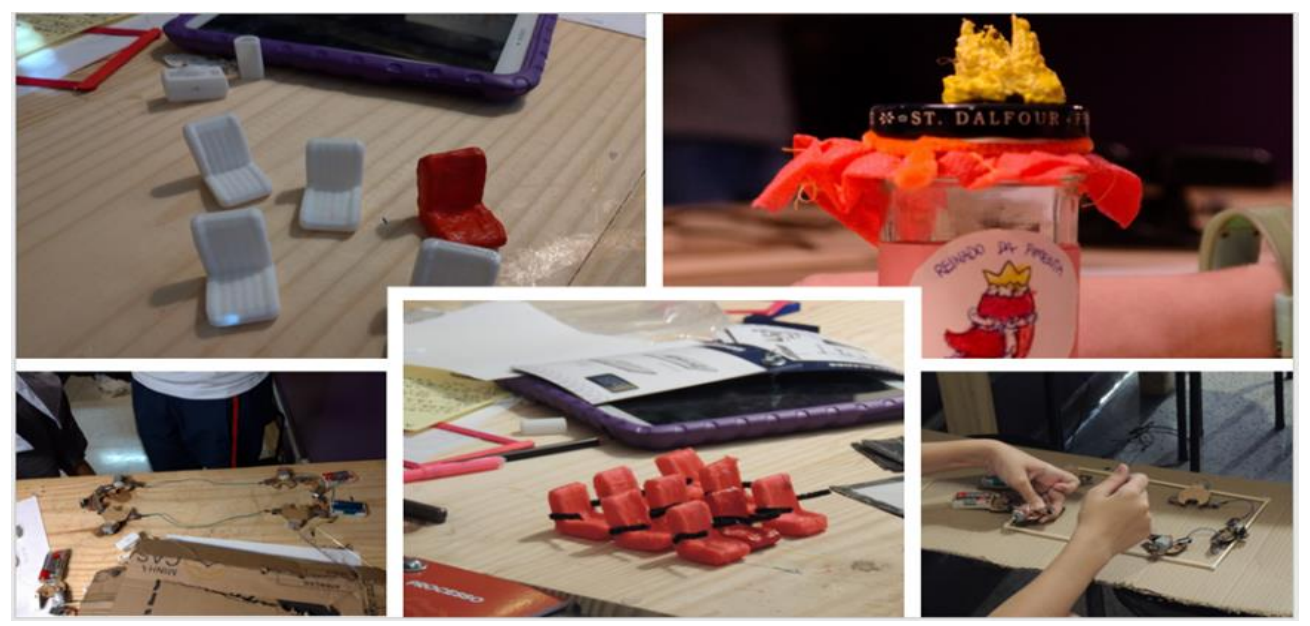

Figura 5 - Prototipação. Resultados dos projetos construídos pelos alunos na etapa de prototipação

Compartilhamento. Intercaladas com a etapa de prototipação as equipes fazem o compartilhamento dos problemas e dificuldades para obter ajuda e validar ideias de todo o grupo.

\subsection{Reflexão}

Apresentação do mapa processual. Após concluírem seus projetos, cada grupo compartilhou, além do produto final de sua construção e do esforço envolvido, todo o processo pelo qual passaram. Para isso, tiveram como apoio um painel de folha kraft no qual foram registrando todas as etapas desde a primeira aula, ressaltando os pontos que acharam mais importantes; compartilharam suas dificuldades, sucessos e descobertas juntamente com seus sentimentos enquanto construíam. 

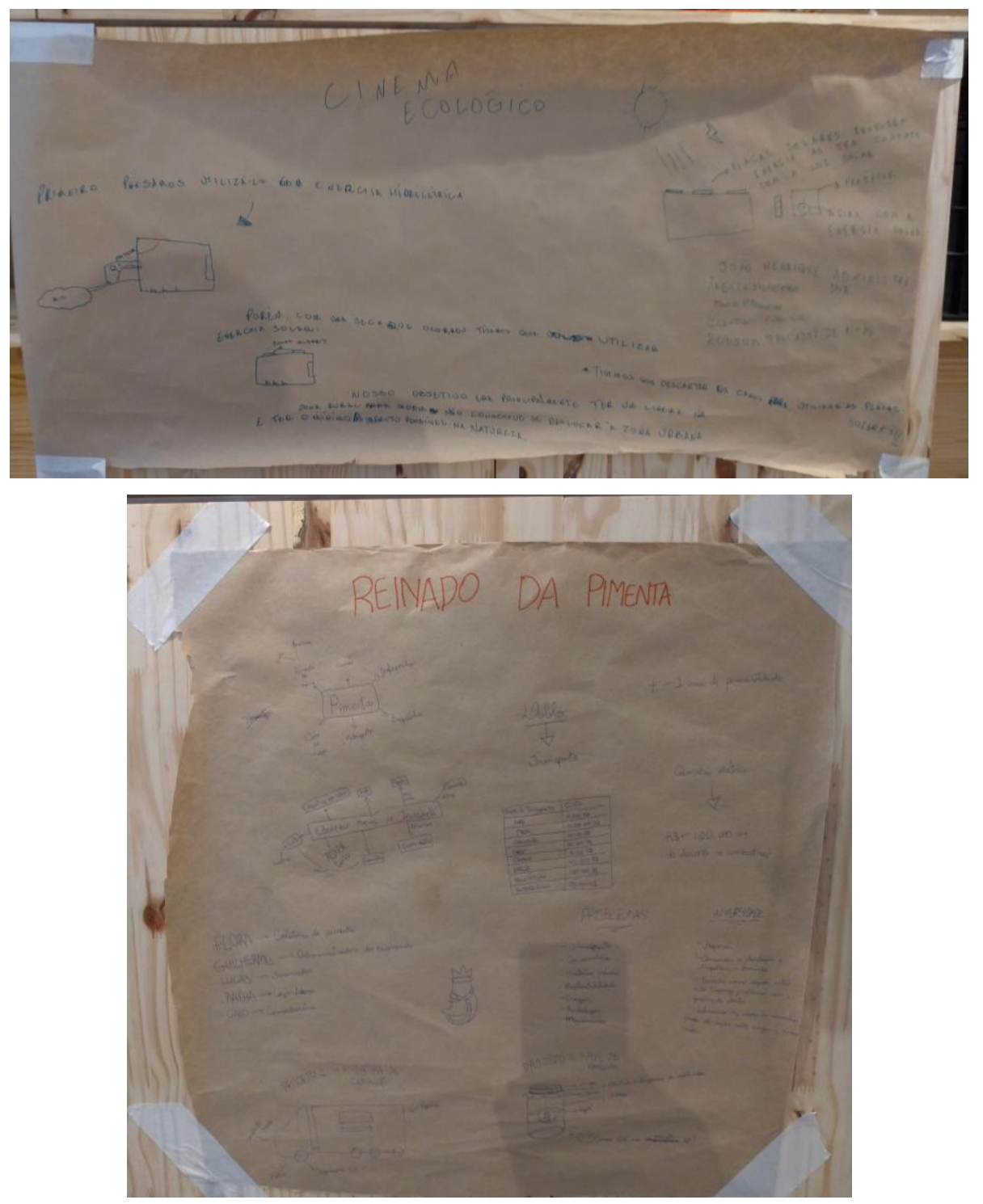

Figura 6 : Mapas processuais elaborados pelos grupos para a apresentação para a turma.

Foi perceptível o quanto ambos os grupos estavam orgulhosos de seus projetos, e mesmo quando houve vergonha de apresentar em público, os colegas de equipe mais extrovertidos comunicaram o papel que cada um desenvolveu ao longo do processo. Além disso, também foi marcante a empolgação e dedicação para preparação do painel que seria apresentado junto com o projeto final, e a reação dos estudantes ante o momento de apresentação: atenciosos com o processo do outro grupo e com performance final do projeto. Como, por exemplo, quando o Maker Beto ligou o sistema de motores do projetor do cinema, causando grande curiosidade ao funcionamento do mesmo, um gancho para que ele explicasse o procedimento de exploração que seguiu.

Conexões. Ao final das apresentações foi feita uma roda de bate papo, onde os Makers discutiram e identificaram os conhecimentos mobilizados durante todo $\mathrm{o}$ processo.

\section{Ser Maker: responsabilidade social, fazer, tecnologia e criatividade.}

O estudo de caso apontado nos permite algumas reflexões sobre a relação entre a atividade maker explorada pelos estudantes e a abordagem CTS, ou seja, entre o ensino da tecnologia e a conscientização social de suas aplicações. Apesar da temática social não 
ser especificamente colocada para os estudantes em nenhum momento do processo, notase que as etapas de ideação, elaboração do projeto, construção e reflexão promovem diversas oportunidades de conexão entre suas criações, saberes técnicos e científicos e os impactos e interações de ambos com o meio natural, social e cultural.

Ao longo do processo, os estudantes passaram por etapas que promoveram a desconstrução de uma percepção baseada no senso comum de que um determinado ambiente, um recorte do mundo rural, seria um lugar atrasado cultural $\mathrm{e}$ tecnologicamente. Isso aconteceu através das curiosidades que o "amigo", ele próprio um personagem que quebra as expectativas de lugar comum, apresenta aos aprendizes. Dessa forma, os estudantes são incentivados a explorar de maneira mais profunda o ambiente apresentado, aproximando-se de novas realidades e entendendo-nas em sua complexidade.

Além disso, as pesquisas em torno de eixos temáticos escolhidos de acordo com seus interesses pessoais, acompanhados de perguntas provocação, cujo objetivo é incentivar questionamentos, investigações e descobertas, suscitaram discussões que perpassam pontos como responsabilidade social, respeito à diversidade cultural, sustentabilidade e responsabilidade ambiental. A organização do material do curso de eixos temáticos como "Animais e Vida", "Recursos Naturais" e "Trabalho, Produção e Infraestrutura", dentre outros, visa colaborar com essas discussões. Visto que os micromundos estabelecem paralelos com aspectos da realidade, a bagagem construída pelos estudantes nos ciclos de aulas poderia contribuir para uma postura consciente e cidadã quando associarem tais discussões a outras situações por eles observadas e vivenciadas.

Soma-se à isso a experiência de colocar-se no lugar do outro proporcionada pela elaboração de personas. Processo esse que estimula o exercício da empatia com o outro, alguém pertencente a um contexto diverso do seu e que deve ser considerado tanto na criação quanto na construção do projeto. Assim, o outro, suas características e necessidades específicas passam a ser parte integrante da perspectiva dos estudantes .

Ainda, fomenta o uso das faculdades criativas, das técnicas aprendidas e das tecnologias disponíveis para a elaboração e construção de projetos que visam um bem comum das personas ou da comunidade do micromundo, consideradas em sua totalidade - social, cultural e ambiental -, como geração de empregos, acesso à cultura e sustentabilidade.

Por fim, incentiva-se o compartilhamento de saberes, técnicas, estudos e soluções ao longo de todo o processo. Reforçando, então, a ideia de que o conhecimento é livre e cresce ao ser partilhado ao mesmo tempo em que contribui para a autonomia dos aprendizes em relação aos saberes disciplinares.

Isso posto, acredita-se que a abordagem que o ensino maker associado às diretrizes da abordagem CTS têm muito a contribuir com a formação integral do sujeito, ponto reforçado pela recém instituída Base Nacional Comum Curricular. No caso apresentado, isso ocorre por meio do exercício de habilidades cognitivas, técnicas e aliadas ao estímulo da formação de uma sensibilidade e responsabilidade social, características essenciais para a produção de uma sociedade mais saudável.

Em conclusão e inspirados pelas elucubrações de Veraszto, Silva, Miranda e Simon (2008) sobre o filme de Stanley Kubrick "2001: Uma Odisseia no Espaço” (1968), propõe-se a seguinte comparação. Em sua fantasia cinematográfica, Kubrick ilustra , na primeira cena do filme, um fenômeno que mudaria para sempre a história da humanidade: 
o advento da primeira ferramenta. O momento em que um hominídeo apropria-se de um fragmento de osso ao encontrar os restos de um grande animal e, num lapso de razão e criatividade, percebe que aquilo poderia transformar seu fazer. Assim, o fragmento deixa de ser apenas um pedaço de mundo inanimado para converter-se em instrumento de intervenção no mundo. Contudo, junto da ferramenta rudimentar, a primeira tecnologia, nasce também a disputa pelo poder, que gera uma fissão no grupo. Essa realidade préhistórica estende-se por séculos e mantém-se como tema do filme: a odisséia humana junto à tecnologia, transformadora, intervencionista e desarmônica. A partir deste cenário, reforça-se a percepção de que o saber técnico não pode ser pensado de forma emancipada da sociedade na qual se desenvolveu. Nesse sentido, entende-se que a educação maker, apesar de não solucionar a questão, poderia aproximar gerações futuras de uma atitude mais consciente diante do saber tecnológico e científico.

\section{Referências}

Brasil. (1998) Ministério da Educação. Secretaria de Educação Fundamental. Parâmetros Curriculares Nacionais: Ciências Naturais. Brasília: MEC/SEF.

Clapp, E. P., Ross, J., Ryan, J. O. e Tishman, S. (2016) Maker-Centered Learning: Empowering Young People to Shape Their Worlds. Jossey-Bass.

Hatch, Mark. (2014) The Maker Movement Manifesto. McGraw Hill Education

Resnick, Mitchel. (2017) Lifelong Kindergarten: Cultivating Creativity Through Projects, Passion, Peers, and Play - MIT Press,

Santos, Verônica Gomes e Galembeck, Eduardo. Aprendizagem Criativa e Significativa Como Trabalhar Ciências Com As Crianças. (2017) XI Encontro Nacional de Pesquisa em Educação em Ciências - XI ENPEC Universidade Federal de Santa Catarina, Florianópolis, SC

Veraszto, E. V.; Silva, Dirceu da ; Miranda, Nonato Assis de ; Simon, Fernanda Oliveira . Tecnologia: buscando uma definição para o conceito. Prisma.com, v. 1, p. 60-85, 2008. 